\title{
Article
}

\section{Psychopathic Processing and Personality Assessment (PAPA): Exploring factor structure}

Lewis, Michael, Ireland, Jane Louise, Ireland, Carol Ann, Derefaka, Gail, McNeill, Kimberley and Birch, Philip

Available at http://clok.uclan.ac.uk/37770/

Lewis, Michael ORCID: 0000-0001-5567-3569, Ireland, Jane Louise ORCID: 0000-0002-5117-5930, Ireland, Carol Ann ORCID: 0000-0001-7310-2903, Derefaka, Gail, McNeill, Kimberley and Birch, Philip (2021) Psychopathic Processing and Personality Assessment (PAPA): Exploring factor structure. Journal of Criminal Psychology, 11 (2). ISSN 2009-3829

It is advisable to refer to the publisher's version if you intend to cite from the work. http://dx.doi.org/10.1108/JCP-03-2021-0008

For more information about UCLan's research in this area go to

http://www.uclan.ac.uk/researchgroups/ and search for <name of research Group>.

For information about Research generally at UCLan please go to http://www.uclan.ac.uk/research/

All outputs in CLoK are protected by Intellectual Property Rights law, including Copyright law. Copyright, IPR and Moral Rights for the works on this site are retained by the individual authors and/or other copyright owners. Terms and conditions for use of this material are defined in the policies page. 


\section{Psychopathic Processing and Personality Assessment (PAPA): Exploring factor structure}

\begin{tabular}{|r|l|}
\hline Journal: & Journal of Criminal Psychology \\
\hline Manuscript ID & JCP-03-2021-0008.R1 \\
\hline Manuscript Type: & Research Paper \\
\hline Keywords: & $\begin{array}{l}\text { Psychopathy, PAPA, Psychopathy factor structure, Sex differences, } \\
\text { Community, Measure development }\end{array}$ \\
\hline \multicolumn{2}{|l}{} \\
\hline
\end{tabular}

SCHOLARONE $^{\mathrm{m}}$
Manuscripts $^{\text {Manusion }}$ 


\section{MANUSCRIPT DETAILS}

TITLE: Psychopathic Processing and Personality Assessment (PAPA): Exploring factor structure

ABSTRACT:

The primary aim was to assess whether the factor structure of the PAPA could be confirmed in a large community sample $(n=1,850)$, comprising three subsamples of adult men $(n=189,248$ and 198) and women ( $n=499,469$ and 247 ). It was predicted that the four-factor solution originally proposed in earlier studies (i.e. dissocial tendencies; emotional detachment; disregard for others; lack of sensitivity to emotion) would be replicated; and produce a multi-dimensional structure consistent across sex.

The current study explored the structure of the newly developed Psychopathic Processing and Personality Assessment (PAPA) among a non-forensic sample.

Although exploratory analysis indicated a four-factor solution, the structure was different with â€ ${ }^{\sim}$ lack of sensitivity to emotionâ $€^{\mathrm{TM}}$ being replaced by â€ responsiveness to perceived aggressionâ $€^{\mathrm{TM}}$. Confirmatory analyses supported this structure among women, yet a three-factor structure was preferred for men that excluded emotional detachment.

The study highlights the importance of attending to sex differences when assessing for psychopathy.

CUST_PRACTICAL_IMPLICATIONS_(LIMIT_100_WORDS) :No data available.

CUST_SOCIAL_IMPLICATIONS_(LIMIT_100_WORDS) :No data available.

This is the first confirmatory factor analysis completed on the PAPA, with the findings conveying its value when assessing for psychopathic traits among a community sample. 
Psychopathic Processing and Personality Assessment (PAPA): Exploring factor structure

Purpose: The current study explored the structure of the newly developed Psychopathic Processing and Personality Assessment (PAPA) among a non-forensic sample.

Design: The primary aim was to assess whether the factor structure of the PAPA could be confirmed in a large community sample $(n=1,850)$, comprising three subsamples of adult men $(n=189,248$ and 198) and women $(n=499,469$ and 247). It was predicted that the four-factor solution originally proposed in earlier studies (i.e. dissocial tendencies; emotional detachment; disregard for others; lack of sensitivity to emotion) would be replicated; and produce a multi-dimensional structure consistent across sex.

Findings: Although exploratory analysis indicated a four-factor solution, the structure was different with 'lack of sensitivity to emotion' being replaced by 'responsiveness to perceived aggression'. Confirmatory analyses supported this structure among women, yet a three-factor structure was preferred for men that excluded emotional detachment.

Research implications: The study highlights the importance of attending to sex differences when assessing for psychopathy.

Originality: This is the first confirmatory factor analysis completed on the PAPA, with the findings conveying its value when assessing for psychopathic traits among a community sample.

KERWORDS: Psychopathy; PAPA; Psychopathy factor structure; Sex differences; Community; Measure development. 


\section{Background}

Psychopathy captures a range of complex behaviours and personality traits, including callousness, egocentricity, irresponsibility, impulsivity and criminality (Dotterer et al., 2017a). It has traditionally been assessed via the Psychopathy Checklist-Revised (PCL-R; Hare, 2003), considered the gold standard for assessing psychopathy (Lynam \& Gudonis, 2005). The PCL-R initially defined the construct through two highly correlated factors, comprising an interpersonal (also known as the 'personality' factor) and a behavioural component. Varying models have since been proposed that question this structure. Some have, for example, outlined a three-factor model identifying affective deficits and omitting antisocial behaviour (e.g. Cooke \& Michie, 2001), and a more recent structure that splits the original personality and behavioural components into interpersonal, affective, lifestyle and antisocial facets (i.e. the four 'facet' model; Hare \& Neumann, 2005). It has become apparent, however, that there remains little consensus on the putative multidimensional structure underpinning this concept.

Psychopathy was traditionally considered as unitary with a single underlying aetiology (e.g. Neumann et al., 2007); yet, multidimensional findings have shifted this focus, and as a by-product, generated interest in exploring psychopathy as a heterogeneous construct manifesting differently across populations (Coid et al., 2012; Miller \& Lynam, 2012; van Dongen et al., 2017). Although predominantly viewed as a forensic concern (Wilks-Riley \& Ireland, 2012), there is growing empirical interest in the factor structure of psychopathy among community samples, where antisocial behaviour is considered absent and more emphasis is instead placed on maladaptive personality traits, which have been argued to be at the centre of 'true' psychopathy (Cleckley, 1982) and therefore become crucial for understanding its structure. 
In response to increased interest in the disorder within normative samples (i.e. nonforensic populations), several psychopathy self-report measures have been developed to assess for abnormal personality traits. This includes the Levenson Self-Report Psychopathy Scale (LSRP; Levenson et al., 1995), the Personality Assessment Inventory (PAI; Morey, 2007), the Psychopathic Personality Inventory - Short Form (PPI-SF; Lilienfeld, 1990), the Triarchic Psychopathy Measure (TriPM, Patrick, 2010), the Self-Report Psychopathy Scale fourth edition (SRP-4; Paulhus et al., 2014), the Psychopathic Personality Traits Scale (PPTS; Budosek et al., 2016), and the Psychopathic Processing and Personality Assessment (PAPA; Lewis et al., 2017). Although use of these measures has been criticised for reasons relating to social desirability, individuals scoring high on psychopathy have, in fact, been identified as producing less positive self-reports (Verschuere et al., 2014). Such measures have also been noted to meaningfully correlate with interview-based approaches to assessment, such as that adopted by the PCL-R (Patrick, 2010). This demonstrates, therefore, some validity in accurately capturing psychopathy.

The availability of psychopathy self-report measures makes them an attractive tool for research purposes (Kelsey et al., 2014), as does their capability to assess the dimensionality of psychopathic traits among those exhibiting lower levels of the disorder (Lilienfeld et al., 2006). However, each self-report is known to differ in their ability to measure the respective traits of psychopathy (Tsang et al., 2018). The LSRP, for example, defines the construct as being underpinned by two stable components closely resembling PCL-R Factor I and II (i.e. primary and secondary psychopathy). The SRP-4 mirrors this to some extent, assessing the four-facet structure underlying the two-factor PCL-R model (Tew et al., 2015). Yet, the PPI deviates from both of these measures and holds general support for two higher order factors among community samples that pertain to fearless dominance and self-centred impulsivity (Ruchensky et al., 2018). A third factor has also been proposed, comprising traits reflective 
of cold-heartedness and carefree non-planfulness (Neumann et al., 2008). According to the TriPM, disinhibition and meanness underpin psychopathy, as does boldness, which in this instance is viewed as both an adaptive (Dotterer et al., 2017b) and maladaptive (Sica et al., 2015) trait.

Despite these differences, factors across measures are known to complement each other by accounting for different latent trait ranges (Tsang et al., 2018). Each self-report may be capturing different but related domains of the concept, thus reinforcing the conceptualisation of psychopathy as a multidimensional construct, as opposed to unidimensional. The use of multiple tools, including the refinement and implementation of newer measures, such as the PAPA, has been recommended to examine a much broader concept of psychopathy (Tsang et al., 2018; Tsang \& Salekin, 2018). This approach is also likely to be advantageous when attending to sex differences, as little is known about the expression of psychopathy in women.

A network analysis of the LSRP, PAI, PPI-SF and SRP among a sample of 1,180 university students ( $n=350$ men and 869 women) identified manipulativeness and irresponsibility/impulsivity to have the strongest central indices within item-level psychopathy models. Using all subscales, social deviance, stimulus seeking and interpersonal affective traits also presented as core domains in the network structure of psychopathy (Tsang \& Salekin, 2018). Marcus et al. (2018) corroborated the importance of interpersonal manipulation, and also defined callousness as a core feature of the disorder, but like Tsang and Salekin, did not examine their relevance to psychopathy to women.

There appears a tendency to overlook sex differences in psychopathy, with much of the literature sampling men, or both sexes, but failing to account for women specifically. Psychopathic traits have largely been associated with antisocial men across a variety of samples (Lilienfeld \& Fowler, 2006); thus, it is this population that has naturally been of 
most interest. However, despite the reported low prevalence of psychopathy among women (Nicholls et al., 2005; Verona \& Vitale, 2006), there is growing evidence to suggest that women also engage in a range of dissocial behaviours relevant to the construct (Hare, 2003; Nicholls et al., 2005). Yet, it is the function and expression of these behaviours that has been noted to differentiate between sex (Hare, 2003). An assessment of psychopathy should ideally consider these differences and measure the construct in both men and women with equal accuracy (Marion \& Sellbom, 2011).

Despite a relative limited evidence base, self-report psychopathy has been identified to operate consistently across sex with few exceptions (Hauck-Filho \& Teixeira, 2014; Miller et al., 2011). For example, when compared to men, women residing in the community were noted to endorse items on the LSRP that conveyed a propensity to manipulate rather than physically harm others, which was the preferred option for men (Gummelt et al., 2012). Divergent relations were also evidenced for impulsivity-related traits on the third version of the self-report psychopathy scale (SRP-III; Neumann et al., 2012). Women were more strongly associated with sensation seeking, an inability to resist urges in the presence of positive affect, and difficulty considering the consequences of one's own behaviour (Miller et al., 2011). There is little empirical explanation for these differences, yet subtle variations in the manifestation of psychopathy have been linked to varying environmental processes, such as adverse early experiences (e.g. Colins et al., 2016; Watts et al., 2017).

Support for a unique maltreatment profile has emerged from a person-oriented analysis performed on a large community sample ( $n=1,186$ men and 1,314 women), which found women exhibiting a psychopathic personality to present with severe emotional difficulties, engage in reactive forms of aggression and more likely to have been exposed to sexual abuse (Colins et al., 2016). Watts et al. (2017) also identified psychopathy and childhood maltreatment to vary as a function of sex, with men expressing boldness traits (i.e. 
stress immunity, fearlessness) as less likely to experience or report adverse early experiences compared to women. Men with pronounced disinhibition and meanness features, however, did report these outcomes.

Childhood maltreatment has been connected to various psychopathologies, including internalising symptoms (e.g. Esteves et al., 2017) and externalising behaviours (e.g. Barch et al., 2018). The range of outcomes has been attributed to disruption of the parent-child attachment characterised by neglect or emotional maltreatment (Pietrek et al., 2013) Indeed, variants of psychopathy have been linked to a unique maltreatment profile, with observed differences in affect elucidating potential mechanisms, or at least providing a pathway for varying expressions of the disorder to form (Dargis \& Koenigs, 2018). This is important to account for since it begins to suggest that there may be functional differences in psychopathy, which arguably could emerge at the trait level and suggesting a more heterogeneous approach to describing and measuring psychopathy can be argued for.

Emotionally abusive relationships experienced during childhood are thought a result of significant levels of distress that are detrimental to a child's ability to relate to others, to interpret others' feelings and perspective take (Dargis \& Koenigs, 2018), as well as increasing their risk of biased, often hostile, responding (Beeney et al., 2015). As such, these relationships are known to give rise to deficits in cognitive and emotional processing, which interact to form a dysfunctional profile that underpins psychopathy (Baskin-Sommers et al., 2011). In terms of affect specifically, the PCL-R was initially stated to broadly capture two forms of opposing emotional difficulties. Factor I was associated with an affective deficit characterised by callous and unemotional traits (i.e. an extreme form of emotional detachment), low levels of negative emotionality, and internalising symptoms (Long et al., 2014). Factor II, in contrast, reflected an affective disturbance representing emotional instability, psychological distress and externalising symptoms (Skeem et al., 2007). A lack of 
empirical support for a complete absence of emotion in Factor I psychopathy (e.g. Derefinko, 2015; Kosson et al., 2018) has seen researchers challenge this conceptualisation.

There is a growing body of evidence for broader emotional disturbances in psychopathy, and which includes the regulation of emotion (Garofalo et al. 2020a). Utilising an offender sample ( $n=268$ men), Garofalo et al. (2018) found emotion dysregulation not to be restricted to behavioural traits (i.e. Factor II), rather the largest effect sizes were identified for the affective and lifestyle domains of psychopathy; thus, extending emotion dysregulation to the affective traits underpinning Factor I. These findings have been corroborated within community samples comprising of men and women (e.g. Garofalo et al. 2019; Garofalo et al. 2020a), and which conveys a role for emotion dysregulation in psychopathy across sex. When considered collectively, such findings also contradict the dual-pathway model (see Fowles \& Dindo, 2009) that equates Factor I psychopathy with intact emotion regulation. Psychopathic individuals thus do not appear to be completely devoid of emotion; instead, their emotional world seems far more complex than originally conceptualised (Ireland et al., 2020) and which is subsequently not well captured within assessments of psychopathy, including self-report.

It has been suggested that greater consideration is to be afforded to emotion in psychopathy as having a functional purpose (Garofalo et al., 2019; Glenn et al., 2017), and where a role for emotion detachment and emotion dysregulation has been proposed (Ireland et al., 2020). The expression of emotion (or in some instances, lack of) has been conceptually considered a mechanism through which psychopathy and dissocial tendencies, such as aggression, present (Garofalo et al., 2019; Garofalo et al., 2020b; Ireland et al., 2020). For instance, evidenced difficulty in refraining from impulsive behaviour in situations of strong emotional arousal (e.g. anger; Kosson et al., 2020) has highlighted a link between emotion dysregulation and more reactive forms of aggression in psychopathy. However, at the 
opposing end of the scale, it is the limited awareness and understanding of emotion (i.e. emotional detachment) that has been conveyed as facilitating more cold, predatory forms of aggression (Garofalo \& Neumann, 2018; Ireland et al., 2020), and thus associated with psychopathic individuals with a callous-affective disposition (Garofalo et al., 2020b). Though there has been limited attention to sex differences in this regard, women have been found to present with a similar pattern of emotional detachment to that evidenced in men (SearaCardoso et al., 2013). Yet, emotion dysregulation has been found to feature more strongly in women exhibiting psychopathic traits (Sevecke et al., 2016).

Nevertheless, there is clear value in attending to emotional functioning when understanding psychopathy as a dynamic construct, and which is also echoed within DeLisi's (2009) unified theory of crime that views psychopathy as a manifestation of criminality regardless of demographic, as well as comprising of various affect challenges which include noticeable differences in how psychopathic individuals experience their emotional world when compared to those absent of psychopathy. Notably, DeLisi's theory considers the core characteristics of psychopathy to embody the conceptual nature of criminality, viewing the construct itself as the motivation for offending, and where emotion has a contextual influence (DeLisi, 2009).

It becomes evident that a multidimensional approach is required when understanding psychopathy, and which naturally extends to its assessment. There is a need to consider the context in which psychopathy manifests, and where there is value in attending to the underlying factors, such as affect, that may determine its expression (Rogstad \& Rogers, 2008). One self-report measure that may attend to these factors more closely is the PAPA, as this tool was developed to explicitly measure disturbances in cognition and affect in psychopathy that arise from developmental challenges. As such, the PAPA is thought to capture more discrete elements of psychopathy that may influence its manifestation and is 
thus not simply a replication of the PCL group of measures (Lewis et al., 2017). The PAPA has established good reliability in men across populations, with construct validity also being evidenced through its ability to correlate with maladaptive schemas (Lewis, 2014), which represent dysfunctional cognition about the self, others and the world arising from difficult childhood experiences. However, its structural properties are yet to be determined in detail, and to comprise women.

The current study aims to further investigate the nature and structure of psychopathy, as defined by the PAPA, and attending specifically to sex differences. Both parallel and confirmatory factor analyses will be employed across three adult community samples of men and women. It was hypothesised that: (1) The original PAPA four-factor solution proposed by Lewis et al. (2017) would be replicated; (2) That the multidimensional structure of the PAPA would be consistent between sex.

\section{Method}

\section{Sample}

Three samples, of which all were recruited online, were employed as follows ${ }^{1}$ :

\section{STUDY I: Participants}

Seven hundred and twenty-five adult participants (189 men and 499 women), sampled from the community. Thirty-seven participants did not disclose their sex. Mean age for the sample was 27.7 years $(\mathrm{SD}=10.2)$ and 27.4 years $(\mathrm{SD}=9.9)$ and 27.8 years $(\mathrm{SD}=$ 10.3) for men and women respectively.

\section{STUDY II: Participants}

Seven hundred and eighteen adult community participants took part (Mean age $=$ 23.4 years, $\mathrm{SD}=8.0)$ of which 248 were men $($ Mean age $=22.7$ years, $\mathrm{SD}=7.5)$ and 469 women $($ Mean age $=23.8$ years, $\mathrm{SD}=8.3$ ). One participant did not indicate their sex. 


\section{STUDY III: Participants}

Four hundred and forty-five adult community participants were recruited (Mean age $=24.4$ years, $\mathrm{SD}=7.5)$. Of these, 198 were men $($ Mean age $=24.3$ years, $\mathrm{SD}=6.9)$ and 247 were women $($ Mean age $=24.6$ years, $\mathrm{SD}=8.0$ ).

\section{Measures}

All completed the Psychopathic Processing and Personality Assessment (PAPA; Lewis et al., 2017). The PAPA comprises 29 statements. One item was omitted from the analysis as it serves as a measure of trait stability rather than psychopathy per se (i.e. 'As a person, I have never changed'). Participants were required to respond to each item via a fivepoint Likert scale ranging from (1) 'very unlike me' to (5) 'very like me'.

\section{Procedure}

A university ethics committee granted ethical approval. Participants completed the PAPA online. All received relevant information prior to consenting and undertaking the research. A debrief form was provided upon completion. Analyses were performed using SPSS and AMOS.

\section{Results}

Initially, the structure of the PAPA was examined in an attempt to confirm its published (Lewis et al., 2017) four-factor structure (STEP I). Following this, exploratory analyses (STEP II) were implemented to determine the presence of sex differences. The final stage (STEP III) was performed to confirm the revisions to the structure of the measure. All models were recursive, were identified and standardised with variances set to 1.00 . 


\section{Data screening}

Little's MCAR test revealed that data was missing at random across all three studies: STUDY I: $x^{2}=351.11, \mathrm{df}=321, p>.05 ;$ STUDY II: $x^{2}=182.75, \mathrm{df}=162, p>.05$; STUDY III: $x^{2}=49.23, \mathrm{df}=54, p>.05$; and replaced using Expectation Maximisation (EM). No univariate outliers were identified. Using Mahalanobis Distance with $p<.001,33$ cases were highlighted as multivariate outliers in STUDY I and deleted from the dataset. A further 42 cases were removed from STUDY II and 14 from STUDY III.

\section{STEP I: Confirming the published four-factor structure of Lewis et al. (2017)}

The first confirmatory factor analysis was performed using data from STUDY I to determine whether the PAPA was unidimensional. The model demonstrated a poor fit with a single latent variable $\left(x^{2}=2503.41, \mathrm{df}=350, p<.001 ; \mathrm{RMSEA}=.09\right.$ [.09-.10]; GFI = .75; $\mathrm{CFI}=.65 ; \mathrm{ECVI}=3.79[3.56-4.02])$.

Following demonstration of a non-unidimensional structure, the aim was to confirm the PAPA structure identified by Lewis et al. (2017), again using the data from STUDY I. Lewis et al. (2017) proposed a four-factor structure comprising dissocial tendencies (seven items), emotional detachment (four items), lack of sensitivity to emotion (seven items) and disregard for others (10 items). A decision was made to explore these factors among the sample as a whole, since Lewis et al. (2017) did not differentiate between men and women when outlining the factor structure. Covariances were added between factors to reflect their correlations. The model produced is illustrated in Figure 1.

\footnotetext{
$<$ Figure 1 to go about here >
} 
The four-factor model demonstrated an acceptable fit $\left(x^{2}=1645.60, \mathrm{df}=347, p<\right.$ $.001 ; \mathrm{RMSEA}=.07$ [.07-.08]; GFI = .85; CFI = .79; ECVI = 2.55 [2.38-2.74]), as RMSEA was below .08 and had a lower ECVI (Hu \& Bentler, 1999). Attending to modification indices and adding item covariances made no significant improvement to model fit ${ }^{2}$. The next step was to explore the PAPA structure across sexes.

\section{STEP II: Exploring the factor structure of the PAPA across sexes}

Inspection of the correlation matrix revealed many coefficients greater than .40 for both men and women. A Kaiser-Meyer-Olkin value of .83 for men and .88 for women was achieved, and Bartlett's test of Sphericity was statistically significant for each sample. Thus, the data was deemed suitable for exploratory factor analysis for both men and women (using STUDY II).

Factor analyses were initially performed separately for men and women. Parallel Analysis (PA) was adopted to more strictly inform the number of factors evident. PA alongside the initial factor outlines and explained variance indicated a four-factor solution that was similar across men and women. Thus, a Principal Components Analysis (PCA) with Varimax Rotation was used on the sample (i.e. men and women combined), as no assumptions about the model were made.

\section{$<$ Table 1 to go about here $>$}

Results are presented in Table 1, along with each item's original positioning in the PAPA and reliability analyses. Four items $(6,11,24$ and 26), 'I have been described as a cruel person who does not worry about hurting others', 'I find it impossible to resist temptation', 'If I do something wrong I will feel bad about it' and 'I always accept 
responsibility for what I do', did not load. Factor 1 was best captured as Disregard for Others; Factor 2 as Emotional Detachment; Factor 3 as Dissocial Tendencies; and Factor 4 as Responsivity to Perceived Aggression. The next step aimed to confirm the revised structure in a sample of men and women using data from STUDY III.

STEP III: Confirming the revised structure of the PAPA

Reliability analyses were performed for each factor separately for men and women. Alphas ranged from acceptable to good, with all item-to-total correlations positive (Men: Factor 1, $\alpha=.83$; Factor 2, $\alpha=.44$; Factor 3, $\alpha=79$; Factor $4=.82$; Women: Factor $1, \alpha=.90$; Factor 2, $\alpha=43$; Factor $3, \alpha=.88$; Factor $4, \alpha=87$ ). The exclusion of item 14, 'I am not that bothered about others', increased the alpha of Factor 2 to .70 for men and .73 for women.

Two confirmatory factor analyses were performed to confirm the factor structure identified during STEP II in men and women separately. Covariances were added between factors to reflect their correlations ${ }^{3}$. For men, the revised four-factor structure demonstrated an acceptable fit $\left(x^{2}=456.98, \mathrm{df}=228, p<.001 ; \mathrm{RMSEA}=.073\right.$ [.06-.08]; GFI $=.83 ; \mathrm{CFI}=$ $.87 ; \mathrm{ECVI}=2.94$ [2.64-3.29]). Attempts to improve this model were made by examining modification indices and adding item covariances. The factor Emotional Detachment appeared to fit the model poorly. Removal of this factor brought the model fit to its optimum where no further improvement could be achieved $\left(x^{2}=296.94, \mathrm{df}=152, p<.001\right.$; RMSEA $=$ .071 [.06-.08]; GFI $=.86 ; \mathrm{CFI}=.90 ; \mathrm{ECVI}=1.98[1.74-2.27])$. This model is presented in Figure 2. 
The four-factor solution demonstrated an acceptable fit among women ${ }^{4}\left(x^{2}=\right.$ 617.07, $\mathrm{df}=228, p<.001 ; \mathrm{RMSEA}=.084[.07-.09] ; \mathrm{GFI}=.80 ; \mathrm{CFI}=.89 ; \mathrm{ECVI}=2.96$ [2.67-3.28]). The addition of an item covariance improved model fit, specifically with regards to GFI and CFI, with a reduction in RMSEA also evidenced $\left(x^{2}=541.53, \mathrm{df}=227\right.$, $p<.001 ; \mathrm{RMSEA}=.076[.07-.08] ; \mathrm{GFI}=.83 ; \mathrm{CFI}=.91 ; \mathrm{ECVI}=2.65[2.39-2.95])$. Figure 3 illustrates this model.

\section{Discussion}

The current study supported the four-factor model delineated by Lewis et al. (2017), in that the PAPA demonstrated an acceptable fit for dissocial tendencies, emotional detachment, lack of sensitivity to emotion, and disregard for others. The prediction was therefore supported. Yet, when attending to sex differences, principal factor analyses revealed a four-factor solution consistent between men and women, which was almost identical to that proposed by Lewis et al. (2017). However, in this instance, a lack of sensitivity to emotion was replaced by a new component; responsivity to perceived aggression. Confirmation of this structure revealed that the four-factor solution was appropriate for women, whilst a three-factor solution excluding emotional detachment provided a more accurate fit for men.

Confirmatory analyses performed on men and women separately demonstrated two interesting findings: (1) that the factors underpinning the PAPA were not distinct and in fact covary; and (2) for men, a three-factor solution was preferable. The first indicated that the factors underpinning psychopathy for both men and women are not distinct and correlate. This finding is comparable to established models of psychopathy (Cooke \& Michie, 2001; Hare, 2003; Hare \& Neumann, 2005) and may suggest that the factors represent a single higher order factor of psychopathy. Analysis of the PAPA as a unidimensional measure 
revealed a poor fit, yet this was completed for the sample as a whole and did not attend to unidimensionality in men and women separately. Thus, the current study indicates that there may be value in administering the PAPA both as a unidimensional and multidimensional measure since it remains unclear as to whether or not focusing on individual factors is of more value than using the higher order factor of psychopathy, when assessing men and women separately.

The factor structure of the PAPA was different for men and women. This did not support the prediction that the multidimensional structure of the PAPA would be replicated between sex; although a four-factor solution was a good fit for women, it was not for men. Psychopathy in men was underpinned by dissocial tendencies, disregard for others, and responsivity to perceived aggression, thus somewhat resembling the interpersonal and behavioural features of the PCL-R. This structure was also relevant to women; however, for women, emotional detachment also emerged as an important factor. The current study therefore indicates that whilst there are shared features, psychopathy does not present in a uniform manner across sex. This is consistent with previous findings (e.g. Gummelt et al., 2012; Miller et al., 2011).

Emotional detachment appeared solely responsible for the structural differences in psychopathy between men and women. The absence of emotional detachment among men is an unusual finding, especially as this characteristic is considered a core diagnostic feature of psychopathy (Hare, 2003; Marcus et al., 2018). Yet, given that the remaining three factors were present for both sexes, it would be unrealistic to assume that the difference in the expression of psychopathy was solely linked to a unique maltreatment profile, as others have previously suggested (Dargis \& Koenigs, 2018). This is not to say that childhood experiences are not responsible for the observed differences in affect, rather it could be suggested that there is a response difference between men and women; it could be speculated, for example, 
that men may experience past aversive events differently to women (Watts et al., 2017) in terms of how it manifests and/or is reported. The latter may be particularly important and what could be identified here is a reporting difference between sex in terms of variables linked to emotional detachment and not an experience difference.

This explanation does not, however, account for responsivity to perceived aggression and a disregard for others. These were identified as important factors for men and women. The presence of these factors may convey a shared rejecting and hostile developmental experience, thus lending itself to an expression or variant of psychopathy consistent across sex. However, it may be that men exhibiting psychopathic traits prefer to externalise their difficulties through antisocial behaviour, as supported by the presence of dissocial tendencies. Women may also use this as a method of coping alongside more internal means, hence the emergence of emotional detachment and the subtle difference in factor structure. Thus, there could be more internalising of difficulties for women. This is, nevertheless, speculative and represents a direction for future research.

The finding for emotional detachment aligns women more closely to the PCL-R Factor I (i.e. the interpersonal/affective features of psychopathy), since it is this component of psychopathy that has been associated with an affective deficit serving to promote a lack of moral emotion (Hare, 2003; Hare \& Neumann, 2005; Skeem et al., 2007). Although there is emerging evidence for emotion dysregulation within this factor (Garofalo et al., 2019), which needs to be considered. Factor II (i.e. impulsive and irresponsible behaviour) relates more to reactive forms of affect; thus, difficulties in regulating emotion. Emotion dysregulation has certainly been evidenced among women presenting with psychopathy (Garofalo et al., 2019; Garofalo et al., 2020a; Sevecke et al., 2016). It could be speculated that for women to report poor management of emotion, they have to first acknowledge this and attend to it. Thus, the findings here may also reflect a reporting bias among women rather than an absence of 
emotion regulation difficulties. Indeed, it may also be that affective disturbances in psychopathy, specifically among women, present along a continuum with detachment at one end of the scale and poor management/regulation at the other, and which would be consistent with more recent thinking (e.g. Ireland et al., 2020). This notion would require psychopathy to be assessed dynamically and is a consideration for future work.

Responsivity to perceived aggression, as a factor, may also relate to emotion regulation difficulties for the sample. Hostility presenting as a form of cognitive impulsivity, notably hostile attribution bias, may in fact represent underlying impulsive/dysregulated forms of emotion, particularly anger, and which would afford further credibility to the notion of emotion having a functional purpose in psychopathy (Garofalo et al., 2019; Glenn et al., 2017). Psychopathy has also been associated with the maladaptive regulation of anger (Kosson et al., 2020) and which appears to be manifesting here. Nevertheless, the proposed interaction between cognition and affect is well documented in the psychopathy literature (Baskin-Sommers et al., 2011) and the occurrence of this factor could provide an example of this mechanism among a community sample. Indeed, the presence of affective difficulties should not be discounted for men, as additional work is required to refine the PAPA and clarify the expression of this particular factor.

Dissocial tendencies have primarily been associated with psychopathy among men in forensic services, yet research (e.g. Nicholls et al., 2005), including the present study, has established a role for antisocial traits within community samples, including women. There is thus evidence of criminality as being a stable characteristic in psychopathy, providing further support for the unified theory (DeLisi, 2009) relevant to the construct. To assess psychopathy in both sexes, measures should continue to attend to these characteristics. This would support the need for a broader assessment of psychopathy so that its heterogeneity (Tsang et al., 2018) and range can be captured more completely across 
samples. Indeed, it seems unusual for a personality construct to be so focused on unique samples, such as a forensic population, when the determination of personality challenges can only be truly considered if there is identification across a broad range of samples. This allows for extremes in personality to be more readily determined. However, psychopathy as a concept has increasingly been focused only on unique, and not community, samples. In addition, whilst the PAPA successfully attended to several core features of psychopathy (i.e. those pertinent to the PCL-R), there are outstanding traits also noted to have utility when assessing in community samples (e.g. the concept of 'boldness'; Watts et al., 2017). Thus, administering a range of self-report tools would prove invaluable when attending to the constellation of traits often associated with this multidimensional construct (Tsang et al., 2018).

The current study is not without its limitations. A broader assessment of psychopathy is encouraged for future research, one that attends holistically to the construct. The role of affect, more specifically, and how this presents on the PAPA warrants further investigation to clarify its lack of association among men, and expression in women. The addition of a 'personality functioning' profile to the PAPA would also enable a more dynamic assessment of psychopathy; one that examines the severity of the disorder as well as capturing core difficulties spanning the domains of interpersonal, cognition and affect. This would mirror more modern approaches to personality assessment (Bender et al., 2011), which are increasingly beginning to emerge, such as the more functional assessment now undertaken as part of the ICD-11 approach to diagnosing personality disorder.

The findings of the current study, nevertheless, illustrate that the PAPA is an internally reliable measure when applied to a sample where psychopathy is expected to present at lower levels, in comparison to forensic samples. However, further exploration is required to determine the generalisability of the current findings to different populations, as 
there is some evidence of heterogeneity in psychopathy. Exploration of the PAPA across samples would also permit the possibility of weighting items, or incorporating population specific components (Lewis et al., 2017), to accurately capture structural differences in psychopathy representative of manifestations and aetiologies that are unique to samples.

The extent to which the measure is ecologically valid in terms of response bias was not examined. Future research may therefore consider use of a deception scale alongside the PAPA to identify individuals who are prone to socially desirable responding. It is also worth noting that despite the present study employing both exploratory and confirmatory analyses, it remains correlational in nature and therefore did not permit an investigation into the expression of the components deemed integral to the PAPA. Understanding the function of these would arguably expose more elusive sex differences in psychopathy and could represent a direction for future focus.

Regardless of accepted limitations, the current study illustrates the importance of attending to sex differences when assessing psychopathy as a multidimensional construct among community samples. Similarities and differences in factor structure between sex were noted, with emotional detachment being relevant only to women. This is not to assume, however, that affect does not have a pertinent role in the expression of psychopathy among men, it may just present more discretely. A valuable focus for future research would be to refine and further develop the PAPA to attend to affect in psychopathy more closely, whilst also extending its focus to include a dynamic measure addressing trait severity and functional impairment.

\section{Disclosure statement}

No conflicts of interest are noted. There has also been no financial interest or benefit arisen from this work. Similarly, the work received no funding. 


\section{Acknowledgements}

Thanks to Laura Room, Carly Coultas, Ellen Green, Jessica Newsome, Desiree

McClelland, Lionie Edwards, Jessica McNabb, Hauwa Onifade and Jenna Fergus for their support with data collection. 


\section{References}

Barch, D. M., Belden, A. C., Tillman, R., Whalen, D., \& Luby, J. L. (2018). Early childhood adverse experiences, inferior frontal gyrus connectivity, and the trajectory of externalizing psychopathology. Journal of American Academy of Child and Adolescent Psychiatry, 57, 183-190. https://doi.org/10.1016/j.jaac.2017.12.011

Baskin-Sommers, A. R., Curtin, J. J., \& Newman, J. P. (2011). Specifying the attentional selection that moderates the fearlessness of psychopathic offenders. Psychological Science, 22, 226-234. https://doi.org/10.1177\%2F0956797610396227

Beeney, J. E., Stepp, S. D., Hallquist, M. N., Scott, L. N., Wright, A. G., Ellison, W. D., Nolf, K. A., \& Pikonis, P. A. (2015). Attachment and social cognition in borderline personality disorder: Specificity in relation to antisocial and avoidant personality disorders. Personality Disorders: Theory, Research and Treatment, 6 , 207-215. https://doi.org/10.1037/per0000110

Bender, D. S., Morey, L. C., \& Skodol, A. E. (2011). Toward a model for assessing level of personality functioning in DSM-5: Part I. A review of theory and methods. Journal of Personality Assessment, 93, 332-346. https://doi.org/10.1080/00223891.2011.583808

Budosek, D., Debowska, A., Dhingra, K., \& DeLisi, M. (2016). Introduction and validation of the Psychopathic Personality Traits Scale (PPTS) in a large prison sample. Journal of Criminal Justice, 46, 9-17. https://doi.org/10.1016/j.jcrimjus.2016.02.004

Cleckley, H. (1982). The mask of sanity (Revised ed.). Mosby, New American Library. 
Coid, J., Freestone, M., \& Ullrich, S. (2012). Subtypes of psychopathy in the British household population: Findings from the national household survey of psychiatric morbidity. Social Psychiatry and Psychiatric Epidemiology, 47, 879-891. https://doi.org/10.1007/s00127-011-0395-3

Colins, O., Fanti, K., Salekin, R., \& Andershed, H. (2016). Psychopathic personality in the general population: Prevalence, manifestation, and associated features across gender. Journal of Personality Disorders, 31, 49-74.

http://dx.doi.org/10.1521/pedi_2016_30_237

Cooke, D. J., \& Michie, C. (2001). Refining the construct of psychopathy: Towards a hierarchical model. Psychological Assessment, 13, 171-188. https://doi.org/10.1037/1040-3590.13.2.171

Dargis, M., \& Koenigs, M. (2018). Two subtypes of psychopathic criminals differ in negative affect and history of childhood abuse. Psychological Trauma: Theory, Research, Practice and Policy, 10, 444-451. https://doi.org/10.1037/tra0000328

DeLisi, M. (2009). Psychopathy is the unified theory of crime. Youth Violence and Juvenile Justice, 7, 256-273. https://doi.org/10.1177\%2F1541204009333834

Derefinko, K. J. (2015). Psychopathy and low anxiety: Meta-analytic evidence for the absence of inhibition, not affect. Journal of Personality, 83, 693-709. https://doi.org/10.1111/jopy.12124

Dotterer, H. L., Waller, R., Neumann, C. S., Shaw, D. S., Forbes, E. E., Hariri, A. R., \& Hyde, L. W. (2017a). Examining the factor structure of the Self-report Psychopathy short-form across four young adult samples. Assessment, 24, 10621079. https://doi.org/10.1177/1073191116640355

Dotterer, H. L., Waller, R., Cope, L. M., Hicks, B. M., Nigg, J. T., Zucker, R. A., \& Hyde, L. W. (2017b). Concurrent and developmental correlates of psychopathic 
traits using a triarchic psychopathy model approach. Journal of Abnormal Psychology, 126, 859-876. http://dx.doi.org/10.1037/abn0000302

Esteves, K., Gray, S. A. O., Theall, K. P., \& Drury, S. S. (2017). Impact of physical abuse on internalizing behaviour across generations. Journal of Child and Family Studies, 26, 2753-2761. https://doi.org/10.1007/s10826-017-0780-y

Fowles, D. C., \& Dindo, L. (2009). Temperament and psychopathy: A dual-pathway model. Current Directions in Psychological Science, 18, 179-183. https://doi.org/10.1111\%2Fj.1467-8721.2009.01632.x

Garofalo, C., \& Neumann, C. S. (2018). Psychopathy and emotion regulation: Taking stock and moving forward. In M. DeLisi (Ed.), Routledge international handbook of psychopathy and crime (pp. 76-97). Routledge.

Garofalo, C., Neumann, C. S., Kosson, D. S., \& Velotti, P. (2020a). Psychopathy and emotion dysregulation: More than meets the eye. Psychiatry Research. https://doi.org/10.1016/j.psychres.2020.113160

Garofalo, C., Neumann, C. S., \& Velotti, P. (2018). Difficulties in emotion regulation and psychopathic traits in violent offenders. Journal of Criminal Justice, 57, 116-125. https://doi.org/10.1016/j.jcrimjus.2018.05.013

Garofalo, C., Neumann, C. S., \& Velotti, P. (2020b). Psychopathy and aggression: The role of emotion dysregulation. Journal of Interpersonal Violence. https://doi.org/10.1177/0886260519900946

Garofalo, C., Neumann, C. S., Zeigler-Hill, V., \& Meloy, J. R. (2019). Spiteful and contemptuous: A new look at the emotional experiences related to psychopathy. Personality Disorders: Theory, Research, and Treatment, 10, 173-184. https://doi.org/10.1037/per0000310 
Gerbing, D. W., \& Anderson, J. C. (1984). On the meaning of within-factor correlated measurement errors. Journal of Consumer Research, 11, 572-580. https://doi.org/10.1086/208993

Glenn, A. L., Efferson, L. M., Iyer, R., \& Graham, J. (2017). Values, goals, and motivations associated with psychopathy. Journal of Social and Clinical Psychology, 36, 108-125. http://dx.doi.org/10.1521/jscp.2017.36.2.108

Gummelt, H. D., Anestis, J. C., \& Carbonell, J. L. (2012). Examining the Levenson SelfReport Psychopathy Scale using a graded response model. Personality and Individual Differences, 53, 1002-1006. https://doi.org/10.1016/j.paid.2012.07.014

Hare, R. D. (2003). The Hare Psychopathy Checklist-Revised. Multi-Health Systems.

Hare, R. D., \& Neumann, C. S. (2005). Structural models of psychopathy. Current Psychiatry Reports, 7, 57-64. https://doi.org/10.1007/s11920-005-0026-3

Hauck-Filho, N., \& Teixeira, M. A. P. (2014). Revisiting the psychometric properties of the Levenson Self-Report Psychopathy Scale. Journal of Personality Assessment, 96, 459-464. https://doi.org/10.1080/00223891.2013.865196

Hu, L., \& Bentler, P. M. (1999). Cutoff criteria for fit indexes in covariance structure analysis: Conventional criteria versus new alternatives. Structural Equation Modeling, 6, 1-55. https://doi.org/10.1080/10705519909540118

Ireland, J. L., Lewis, M., Ireland, C. A., Derefaka, G., Taylor, L., McBoyle, J., Smillie, L., Chu, S., \& Archer, J. (2020). Self-reported psychopathy and aggression motivation: A role for emotions? Journal of Forensic Psychiatry and Psychology, 31, 156-181. https://doi.org/10.1080/14789949.2019.1705376

Kelsey, K. R., Rogers, R., \& Robinson, E. V. (2014). Self-report measures of psychopathy: What is their role in forensic assessment? Journal of 
Psychopathology and Behavioral Assessment, 37, 380-391.

https://doi.org/10.1007/s10862-014-9475-5

Kosson, D. S., Garofalo, C., McBride, C. K., \& Velotti, P. (2020). Get mad: Chronic anger expression and psychopathic traits in three independent samples. Journal of Criminal Justice. https://doi.org/10.1016/j.jcrimjus.2020.101672

Kosson, D. S., McBride, C. K., Miller, S. A., Riser, N. R. E., \& Whitman, L. A. (2018). Attentional bias following frustration in youth with psychopathic traits: Emotional deficit versus negative preception. Journal of Experimental Psychopathology. Advance online publication. https://doi.org/10.5127\%2Fjep.060116

Levenson, M. R., Kiehl, K. A., \& Fitzpatrick, C. M. (1995). Assessing psychopathic attributes in a noninstitutionalized population. Journal of Personality and Social Psychology, 68, 151-158. https://doi.org/10.1037//0022-3514.68.1.151

Lewis, M. (2014). Understanding the affective and cognitive components of psychopathy: Developing a new assessment [Unpublished doctoral dissertation]. University of Central Lancashire.

Lewis, M., Ireland, J. L., Abbott, J., \& Ireland, C. A. (2017). Initial development of the Psychopathic Processing and Personality Assessment (PAPA) across populations. International Journal of Law and Psychiatry, 54, 118-132. https://doi.org/10.1016/j.ijlp.2017.06.006

Lilienfeld, S. O. (1990). Development and preliminary validation of a self-report measure of psychopathic personality [Unpublished doctoral dissertation]. University of Minnesota. 
Lilienfeld, S. O., Fowler, K. A., \& Patrick, C. (2006). The self-report assessment of psychopathy. In C. J. Patrick (Ed.), Handbook of psychopathy ( $1^{\text {st }}$ ed., pp. 107132). Guildford Press.

Long, K., Felton, J. W., Lilienfeld, S. O., \& Lejuez, C. W. (2014). The role of emotion regulation in the relations between psychopathy factors and impulsive and premeditated aggression. Personality disorders: Theory, Research, and Treatment, 5, 390-396. https://doi.org/10.1521/JSCP.2017.36.2.108

Lynam, D. R., \& Gudonis, L. (2005). The development of psychopathy. Review of Clinical Psychology, 1, 381-407. https://doi.org/10.1146/annurev.clinpsy.1.102803.144019

Mahmut, M. K., Menictas, C., Stevenson, R. J., \& Homewood, J. (2011). Validating the factor structure of the self-report psychopathy scale in a community sample. Psychological Assessment, 23, 670-678. http://dx.doi.org/10.1037/a0023090

Marcus, D. K., Preszler, J., \& Zeiger-Hill, V. (2018). A network of dark personality traits: What lies at the heart of darkness? Journal of Research in Personality, 73, 56-62. https://doi.org/10.1016/j.jrp.2017.11.003

Marion, B. E., \& Sellbom, M. (2011). An examination of gender-moderated test bias on the Levenson Self-Report Psychopathy Scale. Journal of Personality Assessment, 93, 235-243. https://doi.org/10.1080/00223891.2011.558873

Marsh, H. W., Lüdtke, O., Nagengast, B., Morin, A. J. S., \& Von Davier, M. (2013). Why item parcels are (almost) never appropriate: Two wrongs do not make a right camouflage misspecification with item parcels in CFA models. Psychological Methods, 18, 257-284. https://doi.org/10.1037/a0032773 
Miller, J. D., \& Lynam, D. R. (2012). An examination of the Psychopathic Personality Inventory's nomological network: A meta-analytic review. Personality Disorders: Theory, Research, and Treatment, 3, 305-326. http://dx.doi.org/10.1037/a0024567

Miller, J. D., Watts, A., \& Jones, S. E. (2011). Does psychopathy manifest divergent relations with components of its nomological network depending on gender? Personality and Individual Differences, 50, 564-569. https://doi.org/10.1016/j.paid.2010.11.028

Morey, L. C. (2007). The Personality Assessment Inventory (PAI). Professional manual ( $2^{\text {nd }}$ ed.). Psychological Assessment Resources.

Neumann, C. S., Hare, R. D., \& Newman, J. P. (2007). The super-ordinate nature of the Psychopathy Checklist-Revised. Journal of Personality Disorders, 21, 102-107. https://doi.org/10.1521/pedi.2007.21.2.102

Neumann, C. S., Malterer, M. B., Newman, J. P. (2008). Factor structure of the Psychopathic Personality Inventory (PPI): Findings from a large incarcerated sample. Psychological Assessment, 20, 169-174. https://doi.org/10.1037/10403590.20.2.169

Neumann, C. S., Schmitt, D. S., Carter, R., Embley, I., \& Hare, R. D. (2012). Psychopathic traits in female and males across the globe. Behavioral Sciences and the Law, 30, 557-574. https://doi.org/10.1002/bsl.2038

Nicholls, T. L., Ogloff, J. R. P., Brink, J., \& Spidel, A. (2005). Psychopathy in women: A review of its clinical usefulness and assessing risk for aggression and criminality. Behavioral Sciences and Law, 23, 779-802.

https://doi.org/10.1002/bsl.678 
Patrick, C. J. (2010). Operationalizing the triarchic conceptualisation of psychopathy: Preliminary description of brief scales for assessment of boldness, meanness, and disinhibition [Unpublished manual]. Florida State University.

Paulhus, D. L., Neumann, C. S., \& Hare, R. D. (2014). Manual for the Self-Report Psychopathy Scale (4 ${ }^{\text {th }}$ ed.). Multi-Health Systems.

Pietrek, C., Elbert, T., Weierstall, R., Müller, O., \& Rockstroh, B. (2013). Childhood adversities in relation to psychiatric disorders. Psychiatry Research, 206, 103110. https://doi.org/10.1016/j.psychres.2012.11.003

Rogstad, J. E., \& Rogers, R. (2008). Gender differences in contributions of emotion to psychopathy and antisocial personality disorder. Clinical Psychology Review, 28, 1472-1484. https://doi.org/10.1016/j.cpr.2008.09.004

Ruchensky, J. R., Edens, J. F., Corker, K. S., Donnellan, M. B., \& Witt, E. A. (2018). Evaluating the structure of psychopathic personality traits: A meta-analysis of the Psychopathic Personality Inventory. Psychological Assessment, 30, 707-718. https://doi.org/10.1037/pas0000520

Seara-Cardoso, A., Dolberg, H., Neumann, C., Roiser, J. P., \& Viding, E. (2013). Empathy, morality and psychopathic traits in women. Personality and Individual Differences, 55, 328-333. https://doi.org/10.1016/j.paid.2013.03.011

Sevecke, K., Franke, S., Kosson, D., \& Krischer, M. (2016). Emotional dysregulation and trauma predicting psychopathy dimensions in female and male juvenile offenders. Child and Adolescent Psychiatry and Mental Health, 10, 1-13. https://doi.org/10.1186/s13034-016-0130-7

Sica, C., Drislane, L., Caudek, C., Angrilli, A., Bottesi, G., Cerea, S., \& Ghisi, M. (2015). A test of the construct validity of the Triarchic Psychopathy Measure in 
an Italian community sample. Personality and Individual Differences, 82, 163168. https://doi.org/10.1016/j.paid.2015.03.015

Skeem, J., Johansson, P., Andershed, H., Kerr, M., \& Louden, J. E. (2007). Two subtypes of psychopathic violent offenders that parallel primary and secondary variants. Journal of Abnormal Psychology, 116, 395-409.

https://doi.org/10.1037/0021-843x.116.2.395

Tew, J., Harkins, L., \& Dixon, L. (2015). Assessing the reliability and validity of the self-report psychopathy scales in a UK offender population. Journal of Forensic Psychiatry and Psychology, 26, 166-184. https://doi.org/10.1080/14789949.2014.981565

Tsang, S., \& Salekin, R. T. (2018). The network of psychopathic personality traits: A network analysis of four self-report measures of psychopathy. Personality Disorders: Theory, Research, and Treatment, 10, 246-256. https://doi.org/10.1037/per0000319

Tsang, S., Salekin, R. T., Coffey, A., \& Cox, J. (2018). A comparison of self-report measures of psychopathy among nonforensic samples using item response theory analyses. Psychological Assessment, 30, 311-327. https://doi.org/10.1037/pas0000481

van Dongen, J. D. M., Drislane, L. E., Nijman, H., Soe-Agnie, S. E., \& van Marle, H. J. C. (2017). Further evidence for reliability and validity of the Triarachic Psychopathy Measure in a forensic sample and a community sample. Journal of Psychopathology and Behavioral Assessment, 39, 58-66.

https://doi.org/10.1007/s10862-016-9567-5 
Verona, E., \& Vitale, J. (2006). Psychopathy in women: Assessment, manifestations and etiology. In C. J. Patrick (Ed.), Handbook of Psychopathy (1 ${ }^{\text {st }}$ ed., pp. 415-436). Guildford Press.

Verschuere, B., Uzieblo, K., De Schryver, M., Douma, H., Onraedt, T., \& Crombez, G. (2014). The inverse relation between psychopathy and faking good: Not response bias, but true variance in psychopathic personality. Journal of Forensic Psychiatry and Psychology, 25, 705-713. https://doi.org/10.1080/14789949.2014.952767

Watts, A. L., Donahue, K., Lilienfeld, S. O., \& Latzman, R. D. (2017). Gender moderates psychopathic traits' relations with self-reported childhood maltreatment. Personality and Individual Differences, 119, 175-180. https://doi.org/10.1016/j.paid.2017.07.011

Wilks-Riley, F., \& Ireland, J. L. (2012). Cognition and psychopathy: Identifying negative and positive schemas in general and forensic samples. Journal of Forensic Psychiatry and Psychology, 23, 466-484. https://doi.org/10.1080/14789949.2012.694464

\section{Footnotes}

[1] The data was derived from a larger dataset of psychopathy projects. The current study is wholly unconnected with the issues addressed in those studies. No structural exploration of the PAPA data has previously been conducted and remains the sole purpose of the present paper.

[2] Although it is well established that highly correlated [within-factor] measurement errors can be added to the model as covariances to improve fit, their use can also result in a loss of 
meaning and therefore should only be adopted with a theoretical justification for doing so (Gerbing \& Anderson, 1984). Item covariances were only included on models where a significant improvement in fit was noted.

[3] Adhering to the guidelines of Marsh et al. (2013), item parcelling was not employed in the present study, as there were an insufficient number of items per factor, and unidimensionality of the constructs at item level for the particular models and sample were not considered. Use of parcelling in this instance would lead to misspecification of items as well as a misleading model fit.

[4] The removal of factor 2, Emotional Detachment, for women worsened the model fit. 


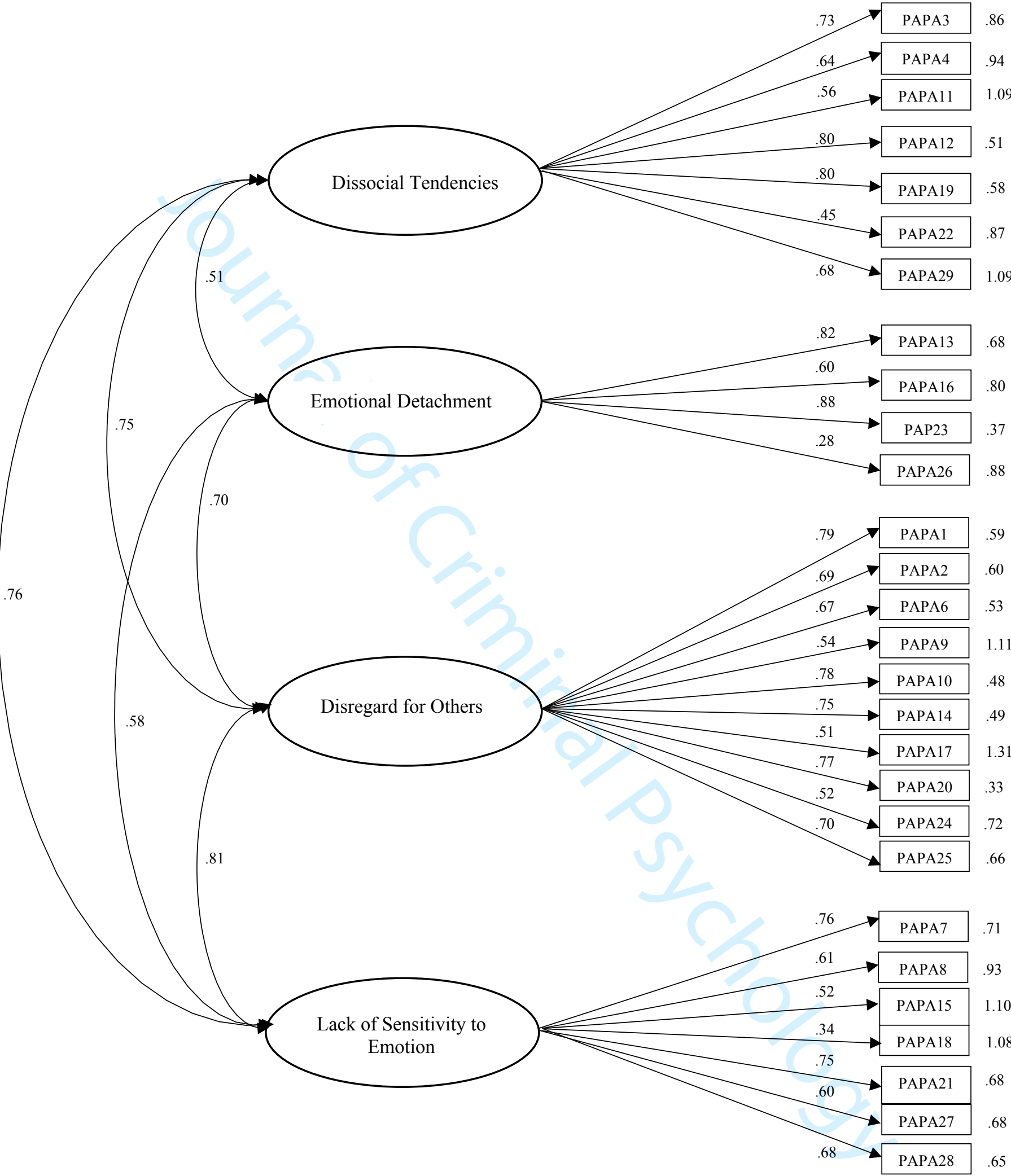

Figure 1. Confirmatory factor analysis of the PAPA factor structure outlined by Lewis et al. (2017) using a community sample $(n=692:$ STUDY I: RMSEA $=.07 ; G F I=.85 ; C F I=.79$; $\begin{array}{lll} & = & 2.55) \text {. }\end{array}$ 
Table 1. Exploratory factor analysis of the PAPA for men and women ( $n=676$; Study II) (NB: Factor loadings are rounded to two decimal places).

\begin{tabular}{|c|c|c|}
\hline & Original PAPA factor & Fac \\
\hline \multicolumn{3}{|l|}{ Factor 1 (24.6\% variance), Disregard for Others; 7 items $\alpha=.76,6$ items $\alpha=.77^{a}$} \\
\hline I will use people to get what I want (PAPA 2) & Disregard for others & .71 \\
\hline I often find myself thinking that I am more important than others (PAPA 25) & Disregard for others & .68 \\
\hline I find most people are weak and not worth bothering with (PAPA 10) & Disregard for others & .58 \\
\hline I am only interested in myself (PAPA 1 ) & Disregard for others & .57 \\
\hline $\begin{array}{l}\text { I can often find myself viewing others as nothing more than 'objects' or things to be used } \\
\text { (PAPA 20) }\end{array}$ & Disregard for others & .57 \\
\hline If I am caught out on a lie I can quickly think of a way out (PAPA 17) & Disregard for others & .55 \\
\hline I regularly view others as lazy (PAPA 9) & Disregard for others & .42 \\
\hline \multicolumn{3}{|l|}{ Factor 2 (8.2\% variance), Emotional Detachment; 5 items $\alpha=.78^{a}$} \\
\hline I find it difficult to give emotional and personal support to others (PAPA 23) & Emotional detachment & .80 \\
\hline I find it difficult to comfort others when they are upset (PAPA 13) & Emotional detachment & .80 \\
\hline I often feel in touch with other people's feelings [reversed] (PAPA 16) & Emotional detachment & .66 \\
\hline I often experience strong positive emotions, such as happiness and joy [reversed] (PAPA 18) & Lack of sensitivity to emotion & .60 \\
\hline I am not that bothered about others (PAPA 14) & Disregard for others & .52 \\
\hline \multicolumn{3}{|l|}{ Factor 3 (6.4\% variance), Dissocial Tendencies; 6 items $\alpha=.76^{a}$} \\
\hline I often get into trouble more than others (PAPA 12) & Dissocial tendencies & .75 \\
\hline $\begin{array}{l}\text { I am able to commit a wide number of behaviours that, if caught, would get me into trouble } \\
\text { (PAPA 19) }\end{array}$ & Dissocial tendencies & .63 \\
\hline As a child, I often got into trouble more than others (PAPA 29) & Dissocial tendencies & .62 \\
\hline I don't think of the consequences of my actions (PAPA 4) & Dissocial tendencies & .61 \\
\hline I often take chances that could be risky to me or others (PAPA 3) & Dissocial tendencies & .56 \\
\hline $\begin{array}{l}\text { I use illegal drugs, or those that are not prescribed to me, more than most people I know } \\
\text { (PAPA 22) }\end{array}$ & Dissocial tendencies & .56 \\
\hline
\end{tabular}

Factor 4 (5.5\% variance), Responsivity to Perceived Aggression; 6 items $\alpha=.73^{a}$ 
Others would describe me as an irritable person with problems controlling my temper (PAPA Lack of sensitivity to emotion

.69 7)

I am an aggressive person in a number of situations (PAPA 21)

Lack of sensitivity to emotion $\quad .64$

I often find people behave aggressively or in a hostile manner towards me (PAPA 27)

Lack of sensitivity to emotion

Lack of sensitivity to emotion $\quad .56$

I see a lot of hostility around me (PAPA 8)

The world is a threatening place, you have to 'watch your back' (PAPA 15)

Lack of sensitivity to emotion $\quad .55$

Others would describe me as a very intense person who has difficulty getting on with others

Lack of sensitivity to emotion

\section{(PAPA 28)}

Items in bold are least likely to form part of the specific factor with loadings below .50 .

a All item-to-total correlations were positive. 


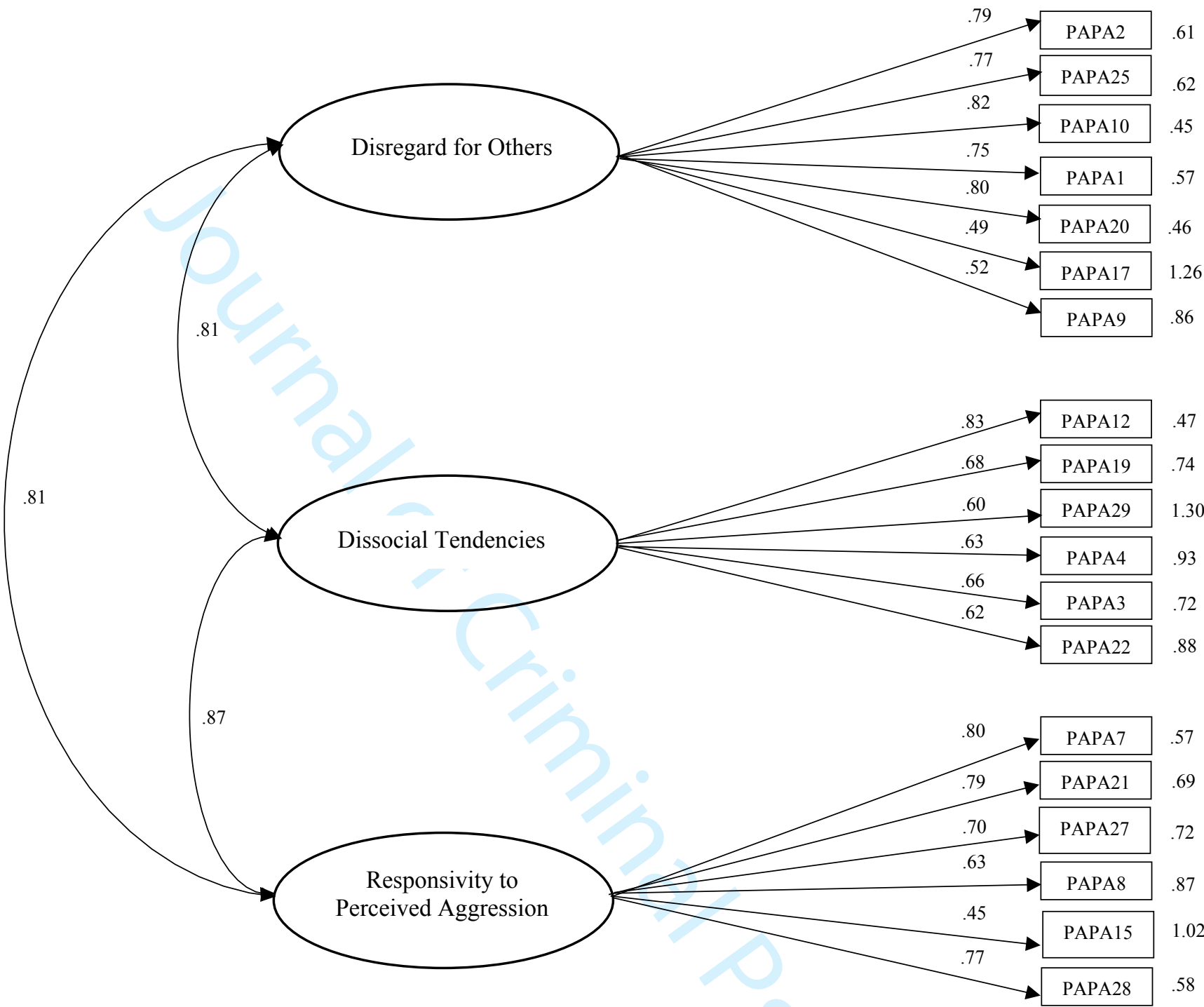

Figure 2. Confirmatory factor analysis of the revised PAPA factor structure among a community sample of men ( $n=189$ : STUDY III: RMSEA $=.071$; GFI =.86; CFI =.90; $E C V I=1.98)$. 


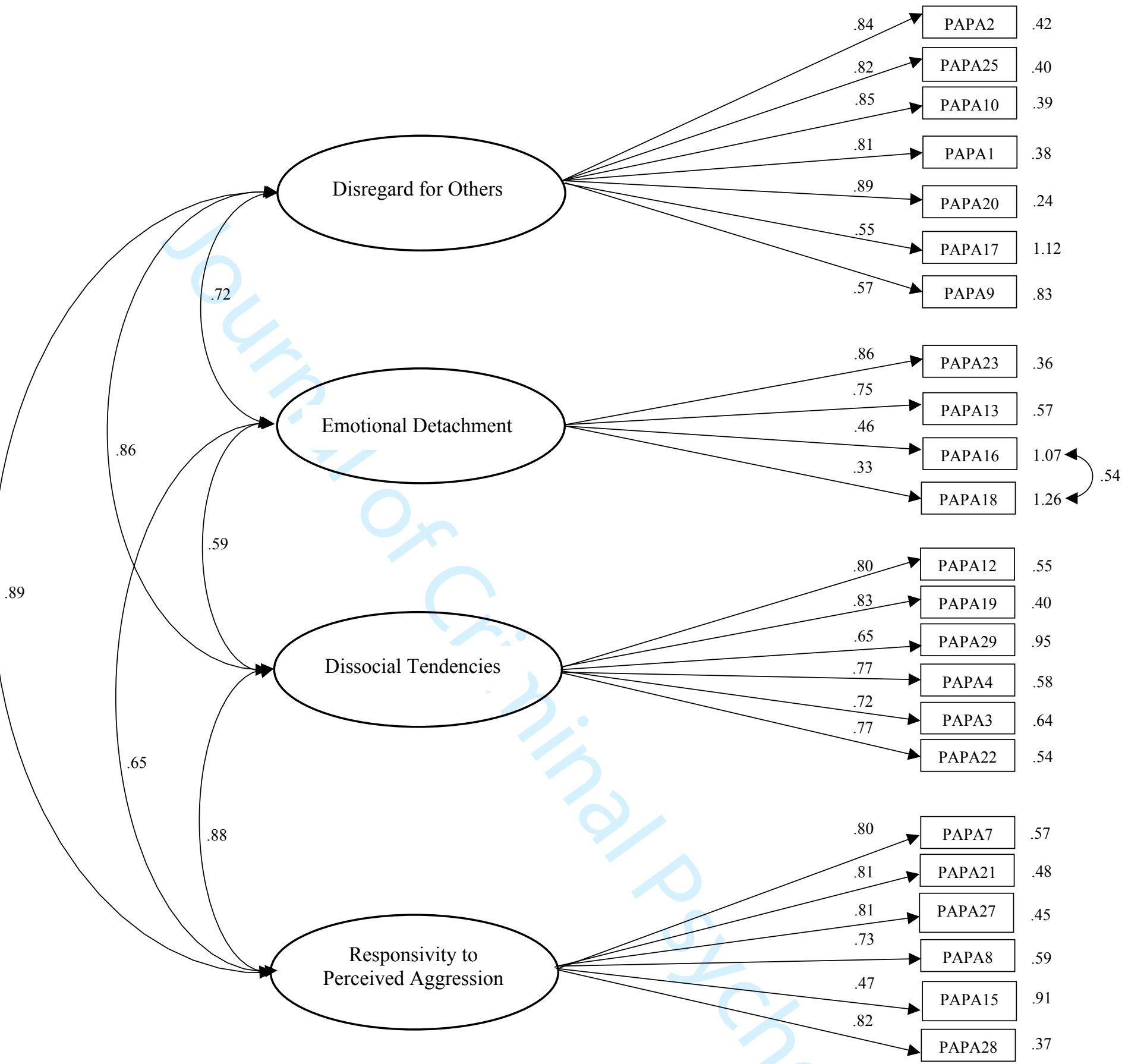

Figure 3. Confirmatory factor analysis of the revised PAPA factor structure among a community sample of women $(n=242:$ STUDY III: RMSEA $=.076 ; G F I=.83 ; C F I=.91$; $E C V I=2.65$. 